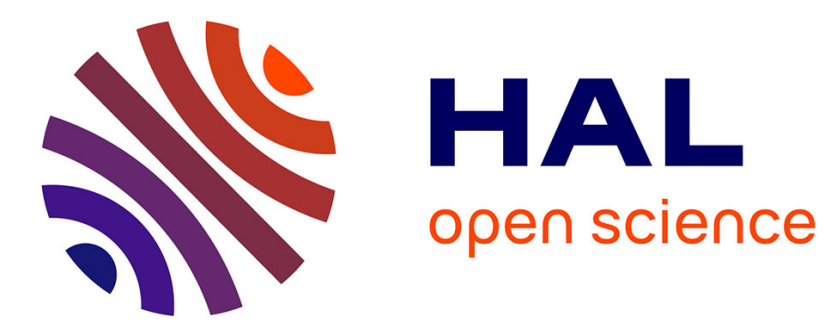

\title{
Effect of compositional variation on optical and structure properties of europium-dopedSiO2-HfO2 glasses
}

Chaofeng Zhu, Andre Monteil, Mohamed El Jouad, Nathalie Gaumer, Stéphane Chaussedent

\section{- To cite this version:}

Chaofeng Zhu, Andre Monteil, Mohamed El Jouad, Nathalie Gaumer, Stéphane Chaussedent. Effect of compositional variation on optical and structure properties of europium-dopedSiO2-HfO2 glasses. Optics Letters, 2009, 34 (23), pp.3749 - 3751. 10.1364/OL.34.003749 . hal-03423756

\section{HAL Id: hal-03423756 \\ https://univ-angers.hal.science/hal-03423756}

Submitted on 10 Nov 2021

HAL is a multi-disciplinary open access archive for the deposit and dissemination of scientific research documents, whether they are published or not. The documents may come from teaching and research institutions in France or abroad, or from public or private research centers.
L'archive ouverte pluridisciplinaire HAL, est destinée au dépôt et à la diffusion de documents scientifiques de niveau recherche, publiés ou non, émanant des établissements d'enseignement et de recherche français ou étrangers, des laboratoires publics ou privés. 


\title{
Effect of compositional variation on optical and structure properties of europium-doped $\mathrm{SiO}_{2}-\mathrm{HfO}_{2}$ glasses
}

\author{
Chaofeng Zhu, André Monteil,* Mohamed EI-Jouad, Nathalie Gaumer, and Stephane Chaussedent \\ Laboratoire des Propriétés Optiques des Matériaux et Applications (POMA), FRE CNRS 2988, Université d'Angers, \\ 2 Boulevard Lavoisier, Angers Cedex 01, 49045, France \\ *Corresponding author: andre.monteil@univ-angers.fr
}

Received September 1, 2009; accepted October 20, 2009;

posted November 10, 2009 (Doc. ID 116605); published November 30, 2009

Glasses with compositions $(100-x) \mathrm{SiO}_{2}-x \mathrm{HfO}_{2}: 0.3 \mathrm{Eu}^{3+}$ (molar ratio, $\left.x=0,10,20,30\right)$ for optical applications were prepared using the sol-gel route. The introduction of hafnium into the glass matrix induced the energy splitting of the ${ }^{7} F_{2}$ state of $\mathrm{Eu}^{3+}$ ions. Furthermore, fluorescence line narrowing (FLN) spectra indicated that $\mathrm{Eu}^{3+}$ clustering occurred in glasses containing no hafnium. The addition of hafnium promoted better dispersion of $\mathrm{Eu}^{3+}$ ions in the glass matrix. The role of hafnium on modifying the properties of glasses was discussed with respect to x-ray diffraction and FLN analysis. () 2009 Optical Society of America

OCIS codes: $160.2750,160.6060,260.3800$.

The incorporation of rare-earth ions (REIs) into silica glasses is of great interest for fundamental studies and technical applications in optical devices such as laser materials, chemical sensors, fiber amplifiers, and waveguides, etc. [1-4]. The optical properties of doped silicate systems depend intimately on the local structure and bonding of dopant cations. Therefore, a detailed understanding of these factors is important from a device engineering perspective. For REIdoped silicate materials, high concentrations of REI are often necessary to achieve good efficiency. Evidence is presented in this Letter suggesting that $\mathrm{Eu}^{3+}$ ions are clustered in sol-gel silicate glasses containing no hafnium. Rare-earth clustering generally has adverse effects, e.g., quenching of the fluorescence, on optical properties. Several researchers have noted that codoping with $\mathrm{Al}^{3+}$ is effective at dispersing REIs in silica gel and silicate glasses [5], but unfortunately the presence of $\mathrm{Al}^{3+}$ also leads to more severe hydroxyl quenching [6].

The goals of the current study are to investigate the effect of hafnium on isolation and luminescence properties of doped $\mathrm{Eu}^{3+}$ ions in silicate glasses produced by the sol-gel method. The effects observed for $\mathrm{Eu}^{3+}$ are expected to impact the development of an understanding of other luminescent-ion-doped sol-gel systems. The results will also assist in the identification of reaction and processing conditions conductive to the establishment of a spatially uniform distribution of luminescent ions in sol-gel materials. To the best of our knowledge, little effort has been made to examine the effect of hafnium on the clustering of $\mathrm{Eu}^{3+}$ in silicate glasses. Also, some previous studies by other researchers indicate that the addition of hafnium into silicate system can adjust the refractive index [7], which enable these materials to be used as valuable candidates for waveguides fabrication. Therefore, the introduction of hafnium in silicate glass systems is scientifically intriguing and could also be technically important to the fabrication of optical devices. $(100-x) \mathrm{SiO}_{2}-x \mathrm{HfO}_{2}: 0.3 \mathrm{Eu}^{3+}(x=0,10,20,30$, molar compositions) glasses were synthesized by using the sol-gel route. The starting solution obtained by mixing tetramethyl orthosilicate (TMOS, purity $>99.0 \%$ ), methanol ( $\mathrm{MeOH}$, analytical reagent grade), and deionized water, in the presence of nitric acid $\left(\mathrm{HNO}_{3}\right)$ as a catalyst, was prehydrolyzed for half an hour at room temperature. The chosen prehydrolysis conditions were TMOS: $\mathrm{MeOH}: \mathrm{H}_{2} \mathrm{O}$ : $\mathrm{HNO}_{3}$ in a 1:6:10:0.6 molar ratio. The appropriate quantity of $\mathrm{HfOCl}_{2} .8 \mathrm{H}_{2} \mathrm{O}$ (purity $>98 \%$ ) was then slowly added to the prehydrolyzed TMOS solution during stirring. Europium was then introduced using $\mathrm{Eu}\left(\mathrm{NO}_{3}\right)_{3} \cdot 6 \mathrm{H}_{2} \mathrm{O}$ (purity $>99.90 \%$ ) in the solutions mentioned above, and the final mixture was let to react under stirring for $2 \mathrm{~h}$ at room temperature. Then the aging and drying process were performed, and some details can be found in our previous papers [5]. The dried gel was heated in air at $1^{\circ} \mathrm{C} / \mathrm{min}$ to $1100^{\circ} \mathrm{C}$ and held at that temperature for $4 \mathrm{~h}$. The emission spectra was measured at room temperature by using the $355 \mathrm{~nm}$ UV light from a Nd:YAG laser. Crystalline structures were evaluated by x-ray diffraction (XRD), using Bruker D8 Advance $\mathrm{x}$-ray diffractometer. Fluorescence line narrowing (FLN) spectra were measured at $77 \mathrm{~K}$ using $532 \mathrm{~nm}$ line of a Nd:YAG laser pumped rhodamine $6 \mathrm{G}$ dye laser setup (Quanta Ray).

The emission spectra of samples with different content of $\mathrm{HfO}_{2}$ are presented in Fig. 1. All spectra were normalized to the peak intensity of ${ }^{5} D_{0} \rightarrow{ }^{7} F_{2}$ transition of $\mathrm{Eu}^{3+}$ around $612 \mathrm{~nm}$ for comparison. The spectra are constituted by a group of emission lines ranging from 570 to $720 \mathrm{~nm}$ that are associated with the transitions from the excited state ${ }^{5} D_{0}$ to the ground levels ${ }^{7} F_{j}(j=0-4)$ of $\mathrm{Eu}^{3+}$ ions. The electronic transitions corresponding to each emission band are indicated in Fig. 1. In the spectrum of samples containing no $\mathrm{HfO}_{2}$, the emission related to the ${ }^{5} D_{0} \rightarrow{ }^{7} F_{2}$ transition exhibits only one peak. While for the samples 


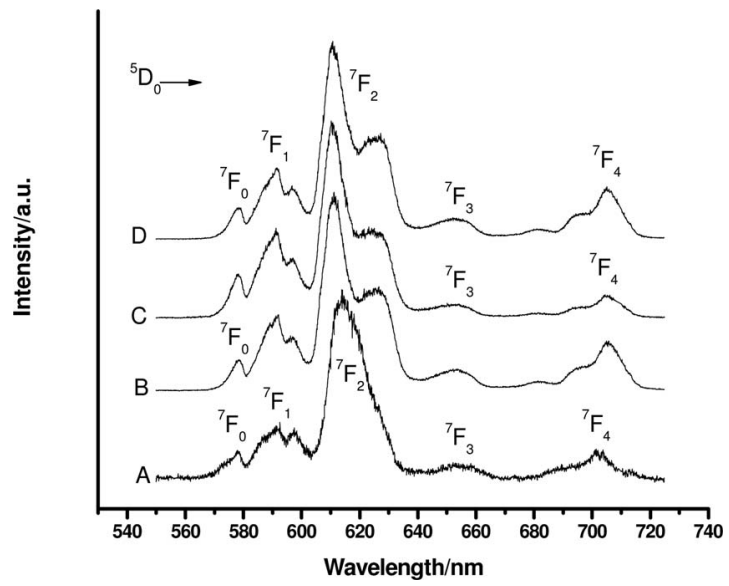

Fig. 1. Emission spectra of $(100-x) \mathrm{SiO}_{2}-x \mathrm{HfO}_{2}: 0.3 \mathrm{Eu}^{3+}$ glasses. A, $x=0 ; \mathrm{B}, x=10$; C, $x=20 ; \mathrm{D}, x=30$.

containing $\mathrm{HfO}_{2}$, the emissions due to the same electronic transition split into two peaks at 610 and $626 \mathrm{~nm}$, which suggest that the environment around $\mathrm{Eu}^{3+}$ ions in samples containing no hafnium is much more different from that in samples containing hafnium. Since the ${ }^{5} D_{0}$ state cannot be split, the number of emission peaks corresponding to the ${ }^{5} D_{0} \rightarrow{ }^{7} F_{2}$ transition is dependent on the energy level splitting of the ${ }^{7} F_{2}$ state. The presence of two emission peaks for the ${ }^{5} D_{0} \rightarrow{ }^{7} F_{2}$ transition in the samples containing $\mathrm{HfO}_{2}$ indicates that the ${ }^{7} F_{2}$ state is separated into two different energy levels.

It is well known that the electric dipole transition ${ }^{5} D_{0} \rightarrow{ }^{7} F_{2}$ is a hypersensitive transition, which is sensitive to the chemical bonds formed between $\mathrm{Eu}^{3+}$ and its surrounding ligands [8]. The luminescence properties of the samples are closely related to the local environment of the $\mathrm{Eu}^{3+}$ site, such as symmetry and Eu-O distance. Figure 2 shows XRD patterns of samples. We can see in Fig. 2 that the sample containing no hafnium remains amorphous. It is obvious that some crystal phases were formed in the samples containing hafnium. The diffraction peaks could be indexed to tetragonal $\mathrm{HfO}_{2}$ crystal phase [9]. The results of XRD analysis indicate that crystal phases exist in the samples containing hafnium, which can in-

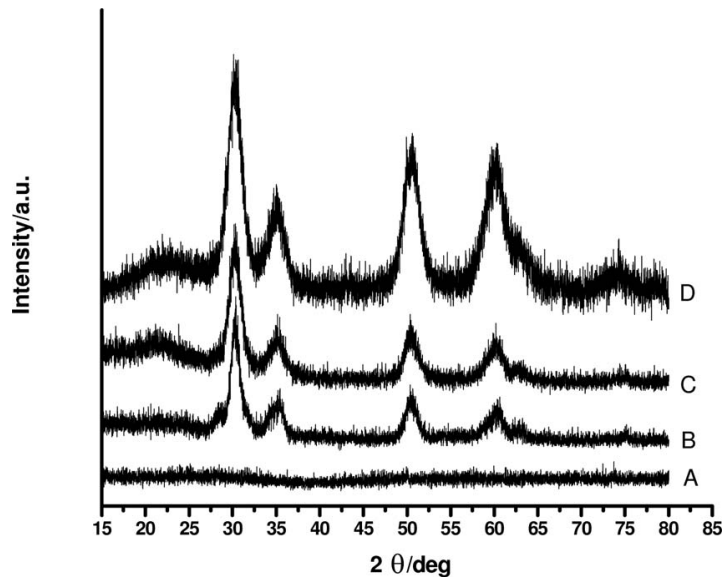

Fig. 2. XRD patterns of $(100-x) \mathrm{SiO}_{2}-x \mathrm{HfO}_{2}: 0.3 \mathrm{Eu}^{3+}$ glasses. A, $x=0 ; \mathrm{B}, x=10 ; \mathrm{C}, x=20 ; \mathrm{D}, x=30$. duce a shortening of Eu-O distance. The overlap between $\mathrm{Eu}^{3+}$ and $\mathrm{O}^{2-}$ orbits with a short Eu-O distance leads to a strong crystal field in the surrounding of $\mathrm{Eu}^{3+}$. On the other hand, energy splitting of the Stark components of the ${ }^{7} F_{2}$ state is caused by the strong crystal field. As a result, energy level splitting at the ${ }^{5} D_{0} \rightarrow{ }^{7} F_{2}$ transition of the $\mathrm{Eu}^{3+}$ ions of the samples containing hafnium occurred, resulting in two emission peaks.

FLN is based on the use of a narrowband excitation source to selectively excite subsets of dopant ions in structurally distinct bonding sites. During the FLN experiment, only the subset of $\mathrm{Eu}^{3+}$ ions with an ${ }^{7} F_{0} \rightarrow{ }^{5} D_{0}$ band resonant with the laser are directly excited. Figure 3(A) presents FLN spectra for $100 \mathrm{SiO}_{2}: 0.3 \mathrm{Eu}^{3+}$ glass. The shape and the peak position of components of the ${ }^{7} F_{1}$ level are independent of the excitation energy, indicating no line narrowing effect, and the absence of site-selective emission was observed for this sample. This phenomenon can be explained by phonon-assisted energy transfer between neighboring $\mathrm{Eu}^{3+}$ ions in the $\mathrm{Eu}^{3+}$ clusters. Clustering of $\mathrm{Eu}^{3+}$ leads to short distances between the $\mathrm{Eu}^{3+}$ ions. Because of this proximity of the ions in the clusters, the $\mathrm{Eu}^{3+}$ ions resonant with the laser can transfer the excitation energy to adjacent nonresonant $\mathrm{Eu}^{3+}$ ions with the simultaneous creation or annihilation of phonons. The phonon-assisted energy transfer process destroys site selectivity, because it provides a mechanism for exciting nonresonant ions. Subsequent emission from the nonresonant ions leads to spectral broadening, resulting in no linenarrowing effect and fluorescence quenching. From the above analysis, clustering of $\mathrm{Eu}^{3+}$ ions occurred and site-selective excitation was not possible with the sample without hafnium. Clustering or aggregation of REIs is undesirable in the synthesis of most optical materials, since clustering generally leads to adverse effects such as concentration quenching. The problems of REI clustering must be eliminated to achieve practical optical devices based on REI-doped sol-gel glasses.

The FLN spectra for $(100-x) \mathrm{SiO}_{2}-x \mathrm{HfO}_{2}: 0.3 \mathrm{Eu}^{3+}$ $(x=10,20,30)$ exhibit nearly similar characteristic. As an example, Figs. 3(B) and 3(C) show the FLN spectra of the samples containing $10 \%$ and $20 \%$ $\mathrm{HfO}_{2}$, respectively. In contrast to the $\mathrm{Eu}^{3+}$-doped $\mathrm{SiO}_{2}$ glass, introducing hafnium into glass matrix significantly affects the FLN spectrum, namely, the relative intensities and peak positions within the ${ }^{5} D_{0} \rightarrow{ }^{7} F_{1}$ and ${ }^{5} D_{0} \rightarrow{ }^{7} F_{2}$ emission bands varied considerably with excitation wavelength, as different subsets of $\mathrm{Eu}^{3+}$ ions within the samples were selectively excited. The ${ }^{5} D_{0} \rightarrow{ }^{7} F_{1}$ band appears to consist of three peaks owing to Stark splitting of the ${ }^{7} F_{1}$ state. The splitting behavior of the Stark components is strongly dependent on excitation energy. For the three emission lines corresponding to the ${ }^{5} D_{0} \rightarrow{ }^{7} F_{1}$ electronic transition, the highest energy line shifts to the higher energy side with increasing excitation energy. In the lower excitation energy range, the three Stark components tend to converge to a triply degen- 

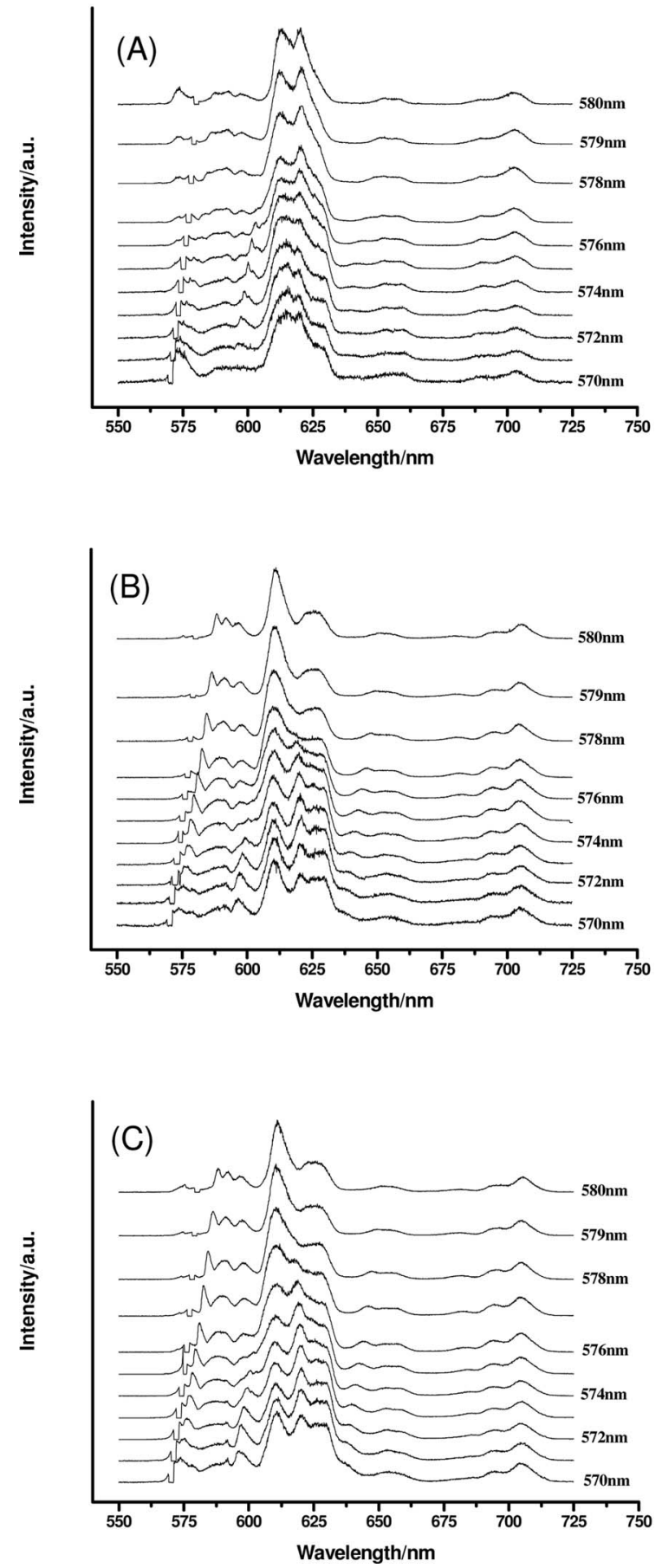

Fig. 3. FLN spectra obtained by selective excitation at different wavelengths between 570 and $580 \mathrm{~nm}$ with a $1 \mathrm{~nm}$ step for $(100-x) \mathrm{SiO}_{2}-x \mathrm{HfO}_{2}: 0.3 \mathrm{Eu}^{3+}$ glasses. The spectra are normalized to the largest peak intensity and excitation wavelength is explicitly indicated in the figure. (A) $x=0$, (B) $x=10$, (C) $x=20$. erate point at around $585 \mathrm{~nm}$ and disperse with increasing excitation energy. Because the ${ }^{7} F_{0} \rightarrow{ }^{5} D_{0}$ excitation energy is a measure of the strength of the crystal field acting on the central $\mathrm{Eu}^{3+}$ ions, such a spectral shift can be attributed to the variation of the local crystal field strength of the $\mathrm{Eu}^{3+}$ ions in glass, which will be discussed in a future paper. From the above analysis, unlike the samples with no hafnium, these spectra show dramatic line-narrowing effects with line-narrowed fluorescence peaks shifting as the excitation wavelength is varied. This fact indicates that the $\mathrm{Eu}^{3+}$ ions do not cluster under codoping with hafnium.

In summary, we have reported the effect of hafnium on the properties of $\mathrm{Eu}^{3+}$-doped $\mathrm{SiO}_{2}-\mathrm{HfO}_{2}$ glasses. The splitting of emission band corresponding to ${ }^{5} D_{0} \rightarrow{ }^{7} F_{2}$ transition of $\mathrm{Eu}^{3+}$ ions occurred for the samples containing hafnium. The results of FLN show that the $\mathrm{Eu}^{3+}$ ions in the glass containing no hafnium have a tendency to form clusters rather than be uniformly distributed throughout the glass, while the presence of hafnium in the glass matrix can disperse and isolate $\mathrm{Eu}^{3+}$ ions, inhibiting cluster formation and leading to the development of a linenarrowing effect.

The authors acknowledge Angers Loire Metropole for a postdoctoral fellowship to Chaofeng Zhu. The authors also express their sincere thanks to Dr. Wenhua Bi (Université d'Angers) for XRD measurements and helpful discussions.

\section{References}

1. J. K. R. Weber, J. G. Abadie, T. S. Key, and K. Hiera, J. Am. Ceram. Soc. 85, 1309 (2002).

2. Y. H. Kim, U. C. Paek, and W. T. Han, Opt. Express 11, 2672 (2003).

3. W. A. Pisarski, T. Goryczka, and J. Pisarska, J. Phys. Chem. B 111, 2427 (2007).

4. S. Berneschi, G. Nunzi Conti, I. Banyasz, A. Watterich, N. Q. Khanh, M. Fried, and F. Paszti, Appl. Phys. Lett. 90, 121136 (2007).

5. A. Monteil, S. Chaussedent, G. Alombert-Goget, N. Gaumer, J. Obriot, S. J. L. Ribeiro, Y. Messaddeq, A. Chiasera, and M. Ferrari, J. Non-Cryst. Solids 348, 44 (2004).

6. B. T. Stone, V. C. Costa, and K. L. Bray, Chem. Mater. 9, 2592 (1997).

7. F. A. Sigoli, R. R. Goncalves, A. S. Camargo, L. A. O. Nunes, Y. Messaddeq, and S. J. L. Ribeiro, Opt. Mater. 30, 600 (2007).

8. D. Jain, V. Sudarsan, R. K. Vatsa, and C. G. S. Pillai, J. Lumin. 129, 439 (2009).

9. N. D. Afify, G. Dalba, C. Armellini, and Y. Jestin, Mater. Sci. Semicond. Process. 9, 1043 (2006). 